1995119512

\subsection{2 44645 \\ N95- 25932}

\title{
APPENDIX T
}

Differential Neutron Energy 8pectra Measured on 8pacecraft in Low Earth Orbit

by

V.E. Dudkin, Yu.V. Potapov, A.B. Akopova, L.V. Melkumyan E.V. Benton and A.L. Frank 


\title{
DIFFERENTIAL NEUTRON ENERGY SPECTRA MEASURED ON SPACECRAFT IN LOW EARTH ORBIT
}

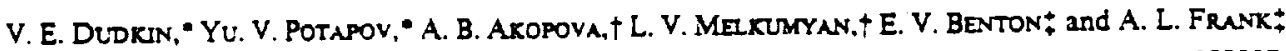 \\ Institure of Biological Problems of the Ministry of Public Health of the U.S.S.R.. Moscow 123007. \\ U.S.S.R.; +Physical Institute. Yerevan, U.S.S.R. and ¥University of San Francisco.\$ California. U.S.A.
}

\author{
(Received 30 May 1989)
}

\begin{abstract}
Two methods for measuring geutrons in the range from thermal energies to dozeas of $\mathrm{MeV}$ were used. In the first method, $x$-paricles emitted from the ${ }^{6} \mathrm{Li}(\mathrm{n} . x) T$ reaction are detected with the belp of plastic nuclear track detectors, yielding results on thermal and resonance neutrons. Also, fission foils are used to detect fast neutrons. Is the second method, fast neutrons are recorded by auclear photographic emuisions (NPE). The results of measurements on board various satelites are presented. The neutron flux density does not appear to correlate clearly with orbital parameters. Up to $50 \%$ of neutrons are due to albedo neutrons from the atmosphere while the fluxes inside the satellites are $15-20 \%$ bigher than those on the outside. Estimates show that the neutron contribution to the total equivalent radiation dose reaches $20-30 \%$.
\end{abstract}

\section{INTRODUCTION}

THE RADUATON environment in low Earh orbits is studied, as a rule, using thermoluminescent dosimeters and plastic nuclear track detectors (Benton et al., 1977; Akatov et al., 1981, 1984). Measurements of this type yield data on absorbed dose, but cannot give informacion on radiation quality or on dose component composition. Also, a serious underestimation may occur because neutrons are disregarded. A few investigations were previously carried out to study the neutron component. The experimental work of Dudkin et al. (1968), Meriker et al. (1970), Jenkins et al. (1971), Bhaff (1976), and calculational efforts of Lingenfelter (1963), Armstrong et al. (1973) and Merker (1973) studied the geutron fluxes and energy spectra in aear-Earth orbits. These previous efforts were, at best, sporadic, so that characteristics of the neutron component in the Earth's environment have not yet been systematically studied.

The aim of the present work was to experimentally study the energy spectra and fluences of neutrons in low Earth orbit as a function of flight parameters. Two methods were used, namely, the method of fission foils with shielding screens and the NPE method. The measured values of aeutron fluxes were then used to estimate the neutron dose equivalent in different energy groups and its contribution to the total equivalent dose.

\section{MEASUREMENT TECHNIQUES}

The large cross-sections for capture of thermal and resonance neutrons by ${ }^{6} \mathrm{Li}$ auclei makes detection possible through the ${ }^{6} \mathrm{Li}(\mathrm{n}, \mathbf{z}) T$ reaction. The fluences of $x$-paricles emitted from ${ }^{6} \mathrm{LiF}$ film surfaces are recorded in plastic nuclear track detectors, for example, in a CR-39 detector. Thermal geutrons can be separated from resonance neutrons using $\mathrm{Gd}$ foils which shield a detector. In our experiment, $25 \mu$ m-thick foils were used. The difference berween shielded and non-shielded detectors gives the value of thermal neutron flux, whereas the shielded detectors measure resonance neutron fuxes. The $4.5 \mathrm{mg} \mathrm{cm}^{-2}$ ${ }^{\prime} \mathrm{LiF}$ thickness defines the detector sensitivity to thermal neutrons which is $4.9 \times 10^{-3}$ tracks ithermal neutron. The sensitivity to resonance neutrons $(0.2 \mathrm{eV}-1 \mathrm{MeV})$, where the dependence of the neutron spectrum was assumed to be $\left(1 / E_{\mathrm{a}}\right)$, was calculated to be $2.56 \times 10^{-4}$ tracks/resonance neutron. The fluence of high-energy neutrons ( $\geqslant 1.0 \mathrm{MeV}$ ) was roughly estirated using thorium foils. The foils recorded the track densities produced by $\mathrm{Th}$ fission fragments. The disintegrations were caused by fast neutrons and by protons. Therefore, to separate neutrons and protons it was necessary to assume the forms of their energy spectra and their relative intensities.

The differential fast-neutron spectrum was determined by the NPE method using the low-sensitivity $400 \mu \mathrm{m}$-thick BYa-type emulsion layers whose recording power corresponds to paricles whose linear energy transfer (LET) exceeds the LET of protons with kinetic energy of about $50 \mathrm{MeV}$. The background from paricles with lower LET values was reduced by this method.

The fast-neutron spectrum was recovered using the recoil proton energy spectrum generated as a result

§̧USF work partially supported by NASA-Ames Research Center Grant No. NCC2-521, and NASA-Johnson Space Center Grant No. NAG9-235.

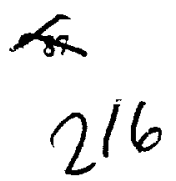


of the elastic (n.p)-scattering of neutrons from the hydrogen in the emulsion.

The recoil proton pach in an exposed and developed emulsion was determined by measuring two orthogonal projections of a track whose ends were located within the volume of an NPE layer. Allowance was made for the fact that a fraction of the recoil protons will leave the emulsion laver and that the probability of such an event rises with increasing recoil proton energy and, hence, the energy of a neutron scattered by the recoil proton. The factor $f$, which depends upon proton energy and NPE layer thickness, was introduced into the recoil-proton path (energy) distribution to cortect for the loss of tracks. To correctly construct the proton path (energy) distribution in NPE, the NPE shrinkage factor $K_{\text {st }}$ was also included.

The kinematics of elastic scattering of a nonrelativistic neutron of energy, $E_{\mathrm{a}}$, has been described elsewhere (e.g. Nemerz and Gofman, 1975). The relationship of the differential neutron energy spectrum $\mathrm{d} N / \mathrm{d} E_{\mathrm{a}}$ to the measured differenual recoil proton spectrum $\mathrm{d} P / \mathrm{d} E$ is found by graphic differentiation and can be presented as

$$
\frac{d N}{d E_{\mathrm{a}}}=-\frac{\mathrm{d}}{\mathrm{d} E}\left(\frac{\mathrm{d} P}{\mathrm{~d} E} \cdot \frac{1}{f(E)}\right) \frac{E_{\mathrm{v}}}{\pi_{0} \cdot \sigma\left(E_{\mathrm{a}}\right) \cdot V}
$$

where $r_{0}$ is the number of hydrogen nuciei in $1 \mathrm{~cm}^{3}$ of NPE $\left(n_{0}=3.05 \times 10^{22} \mathrm{~cm}^{-3}\right.$ for the BYa-type emulsion; $V$ is the volume of emulsion inspected (in $\mathrm{cm}^{3}$ ); $\sigma$ is the $(n, p)-s c a t t e r i n g$ cross-section (in (III))

To facilitate the graphic differentiation, we approximated the recoil proton spectrum including the correction factor $f$ for the track extending beyond the NPE layer. The values of $f$ as a function of proton energy, $E_{p}$, were calculated by the formulas presented in Perfilov et al. (1962), where the expression is of the type

$$
y=\sum_{i} x_{i} \cdot \exp \left(-\beta_{i} E\right)
$$

where $\alpha_{i}$ and $\beta_{i}$ are numerical factors.

The following three circumstances should be noted. Firstly, the measuremeats appear to be unreliable at neutron energies $E_{\mathrm{q}}<1.0 \mathrm{MeV}$ because of a large visual error when recording the shor pach-length protons (the $1 \mathrm{MeV}$ proton path in NPE is $\sim 14 \mu \mathrm{m}$ ). Also, the measurements in the above-mentioned energy range are unreliable because the reacuions of thermal and intermediate neutrons on nitrogen of the emulsion produce a $0.7 \mathrm{MeV}$ neutron which cannot in practice be distinguished from a recoil proton in the (n,p) scattering. Secondly, the error of the given method increases at neutron energies above $10-15 \mathrm{MeV}$ because the expression (1) has been obtained assuming an isotropic proton seattering in c.m.s. which is only possible at energies below $10-15 \mathrm{MeV}$. Thirdly, it should be borne in mind that. if the neutron spectrum is of a complicated non-monotone characte:, a differentiation extor will distor the results substantially.

The reproducibility of this method in the deutron energy range above $1.0 \mathrm{MeV}$ was verified by iradiating similar BYa-type emulsion packages with neutrons from sources whose specira bave been well documented in literature. For example, we irradiated the BYa-type emulsion packages with neutrons from s2 $\mathrm{Cf}$ and from Pu-Be sources, and obtained spectra which differed from published data by not more than $\pm 20 \%$.

\section{RESUTTS AND DISCUSSION}

Flux densities and energy spectra of peutrons in different energy ranges were measured on board several U.S. and Soviet spacecraft The measurements were made inside the satellites and on their external surfaces. The thickness of matter screening the detector inside a satellite was different in difierent sateilites and varied from $\sim 5$ to $\sim 50 \mathrm{~g} \mathrm{~cm}^{-2}$. Unfortunately, the exact distribution of the mass of detectot-surrounding matter was not known. thereby making the analysis of the measurement results dificult.

Table I presents some of the results of measuring neutron flux density on board various spacecraft with 'LiF detectors and fission foils (Benton and Henke, 1983 and Benton, 1986). The table also presents the neutron doses calculated on the basis of these measuremeats.

The doses were calculated using the flux-dose conversion factors from NCRP Proceedings of 1971 , while the quality factors were taken to be $2.0,6.4$, and 10.0 for thermal, resonance and fast neutrons, respectively.

The data on the forms of the neutron and proton spectra used in calculating the doses were taken from Mericer (1973) and Hewitt et al. (1972), respectively, whije the relation between the proton and neutron fluences was aken from Fishman (1974). It should be noted that whereas the experimental data on proton spectra in similar flights generally can be found, the fast-neurron spectral data were not available. Obviously, this circumstance can give rise to probable errors in determining the doses which are difficult to estimate. Since, as seen from Table 1, the fast neutrons make the major contribution to the neutron dose, the method of using the fission foils needs further refinement.

Table 2 presents the results of measuring the fux density of fast $\left(E_{\mathrm{z}} \geq 1 \mathrm{MeV}\right.$ ) neutrons on board varjous satellites of the Cosmos series by the NPE mechod. In each case, the differential neutron energy spectrum was measured and then used to find the neuton flux density by energy integration. The Table 2 results also show the dose equivalent rates obrained using the differential neutron spectra and the fux densiry-dose rate conversion factors taken from Vikhrov et al. (1978). 


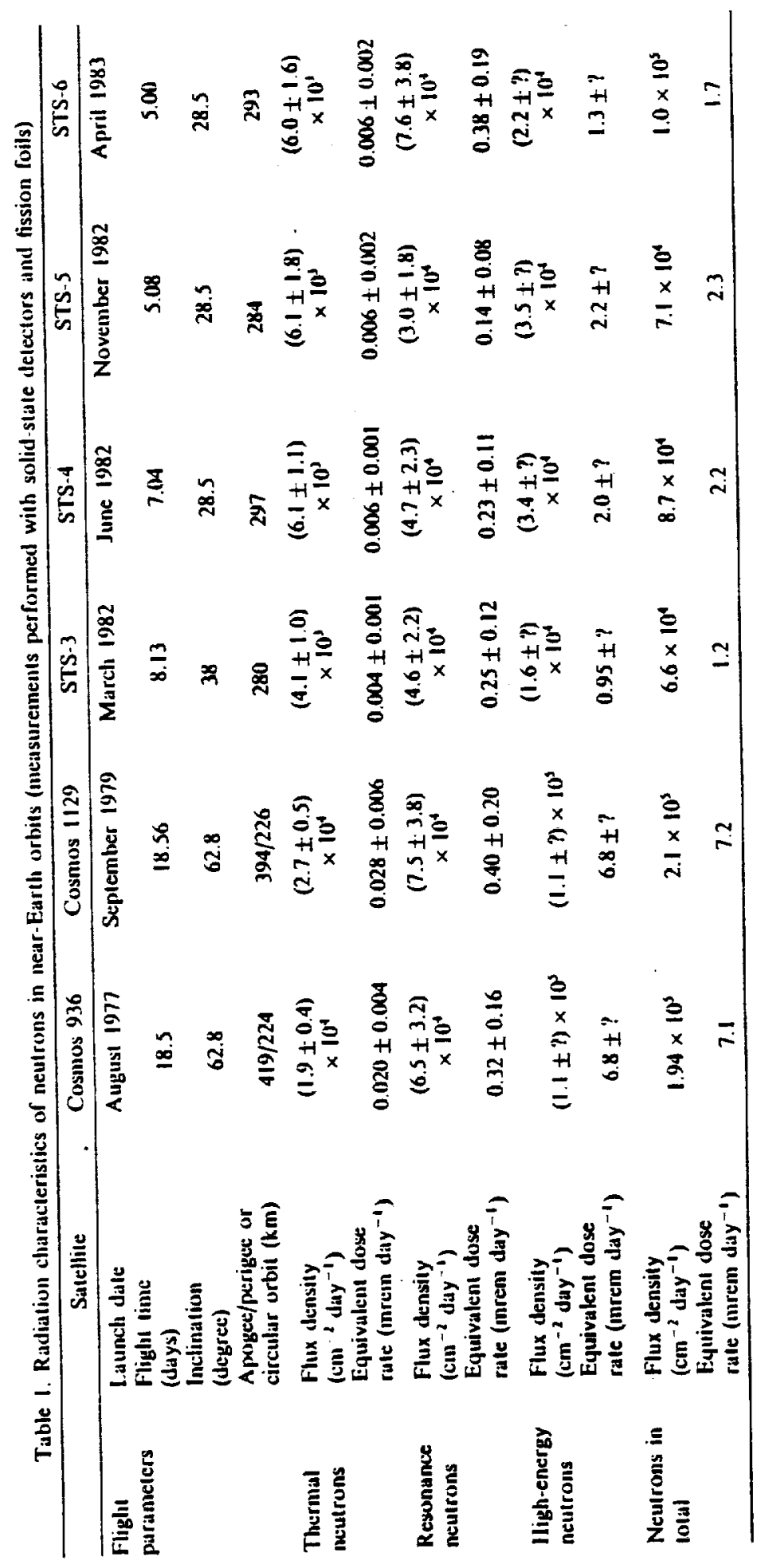


Table 2. Radiation characteristics of fast neutrons in near-Earth orbits (measurements by the NPE method)

\begin{tabular}{|c|c|c|c|c|c|c|c|}
\hline \multirow{2}{*}{$\begin{array}{l}\text { A Cosmos } \\
\text { series } \\
\text { satellite } \\
\text { (number) }\end{array}$} & \multicolumn{4}{|c|}{ Flight parameters } & \multirow[b]{2}{*}{$\begin{array}{c}\text { NPE } \\
\text { placed }\end{array}$} & \multirow[b]{2}{*}{$\begin{array}{c}\text { Neutron fiux } \\
\text { density } \\
\left(\mathrm{cm}^{-2} \text { day }^{-1}\right)\end{array}$} & \multirow[b]{2}{*}{$\begin{array}{c}\text { Equivalent } \\
\text { dose rate } \\
\text { (mrem day }{ }^{-1} \text { ) }\end{array}$} \\
\hline & Launching data & $\begin{array}{c}\text { Time of } \\
\text { flight } \\
\text { (days) }\end{array}$ & $\begin{array}{c}\text { Inclination } \\
\text { (degrees) }\end{array}$ & $\begin{array}{c}\text { Apogee } \\
\text { perigee } \\
(\mathrm{km}) \\
\end{array}$ & & & \\
\hline $\begin{array}{l}936 \\
1129 \\
1129 \\
1514 \\
1514 \\
1571 \\
1600 \\
1667^{*} \\
1667^{*} \\
1757 \\
1781 \\
1887 \\
1887\end{array}$ & $\begin{array}{l}3 \text { August } 1977 \\
25 \text { September } 1979 \\
25 \text { September } 1979 \\
14 \text { December } 1983 \\
14 \text { December } 1983 \\
11 \text { June } 1984 \\
27 \text { September } 1984 \\
10 \text { July } 1985 \\
10 \text { July } 1985 \\
11 \text { June } 1986 \\
17 \text { September } 1986 \\
29 \text { Seprember } 1987 \\
29 \text { September } 1987\end{array}$ & $\begin{array}{l}18.5 \\
18.56 \\
18.56 \\
4.92 \\
4.92 \\
15.3 \\
13.2 \\
7.0 \\
7.0 \\
14.0 \\
14.0 \\
12.6 \\
12.6\end{array}$ & $\begin{array}{l}62.8 \\
62.8 \\
62.8 \\
82.3 \\
82.3 \\
70 \\
70 \\
82.7 \\
82.7 \\
82.3 \\
70.4 \\
62.8 \\
62.8 \\
\end{array}$ & $\begin{array}{l}419: 224 \\
394 / 226 \\
394 / 226 \\
288 / 226 \\
288 / 226 \\
420 / 355 \\
420 / 355 \\
297 / 222 \\
297 / 222 \\
252 / 189 \\
405 / 217 \\
394 / 226 \\
394 / 226\end{array}$ & $\begin{array}{l}\text { inside } \\
\text { inside } \\
\text { outside } \\
\text { inside } \\
\text { outside } \\
\text { outside } \\
\text { outside } \\
\text { outside I } \\
\text { outside II } \\
\text { outside } \\
\text { outside } \\
\text { inside } \\
\text { outside }\end{array}$ & $\begin{array}{l}(1.1 \pm 0.5) 10^{5} \\
(1.1 \pm 0.4) 10^{5} \\
(8.6 \pm 2.6) 10^{4} \\
(7.4 \pm 2.2) 10^{4} \\
(6.2 \pm 1.7) 10^{4} \\
(6.9 \pm 1.7) 10^{4} \\
(7.8 \pm 2.6) 10^{4} \\
(6.7 \pm 1.7) 10^{4} \\
(5.6 \pm 1.7) 10^{4} \\
(5.2 \pm 1.7) 10^{4} \\
(5.2 \pm 1.7) 10^{4} \\
(5.2 \pm 1.7) 10^{4} \\
(4.5 \pm 1.7) 10^{4}\end{array}$ & $\begin{array}{l}4.5 \pm 2.2 \\
4.5 \pm 1.4 \\
3.5=1.0 \\
3.0 \pm 0.9 \\
2.5 \pm 0.7 \\
2.8=0.7 \\
3.1 \pm 1.0 \\
2.7 \pm 0.7 \\
2.2 \pm 0.7 \\
2.1 \pm 0.7 \\
2.1 \pm 0.7 \\
2.1=0.7 \\
1.8 \pm 0.7\end{array}$ \\
\hline
\end{tabular}

- External assembiy I oriented towards the Sun: assembly II oriented towards the Earth.

Shown as an example in Fig. I are the neutron energy spectra measured inside and outside the Cosmos 1514 and 1887 satellites. For comparison, Fig. I presents also the results of a calculated albedo neutron spectra obtained in Lingenfelter (1963) for solar minimum at different orbital inclinations to the plane of the equator $\left(i=40^{\circ}\right.$ and $\left.90^{\circ}\right)$.

Analyzing the experimental data has shown that most of the fast-neutron energy spectra are of the characteristic 'evaporation' form with a maximum in the $1.5-4.0 \mathrm{MeV}$ neutron energy range. In any case. the form of neutron spectra presented here is realized in all the spectra measured inside the spacecraft. The external neutron spectrum is, as a rule, softer.

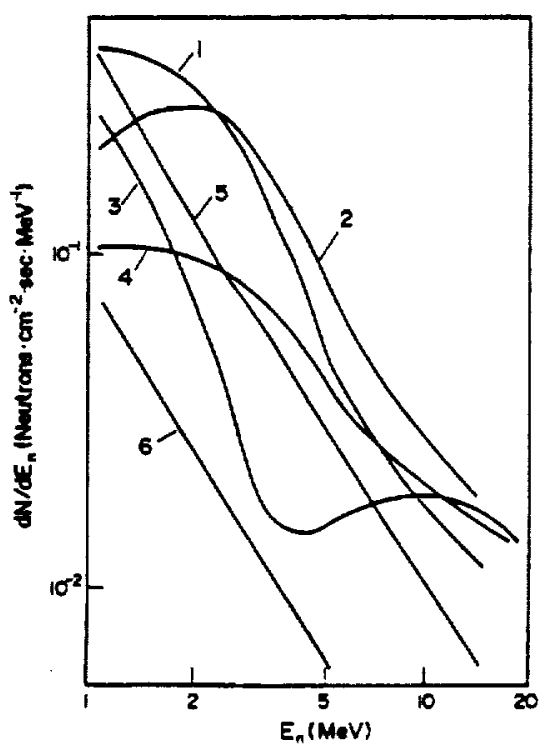

Fig. 1. Differential neutron energy spectra measured in spacectaft in low Earth orbit. Curves 1 and 2 are the Cosmos 1514 data obtained outside (1) and inside (2) the satellite. Curves 3 and 4 are the Cosmos 1887 data obtained outside (3) and inside (4) the salellite. Curves 5 and 6 are the albedo neutron spectra calculated in Lingenfelter (1963) at angle $i=90^{\circ}(5)$ and at $i=40^{\circ}(6)$ during solar minimum.
According to the present-day concepts, the detected neutrons originate from two sources, namely, the albedo neutrons produced in interactions of galactic cosmic rays with the Earth's atmosphere and the secondary neutrons produced in the spacecraft structure (the local neutrons). The form of the local neutron spectra is similar to the form of the spectra generated in inelastic proton-nuclear interactions. The local neutron spectra are obviousiy more rigid compared with the spectra of the albedo neutrons which undergo multiple scatterings and attenuation in the atmosphere.

The data of Table 2 show that the neutron fluences inside the spacecraft are $15-20 \%$ higher than on the outside, thereby indicating that local neutrons are accumulated in the instruments simuitaneously with attenuation of albedo neutrons. This trend is observed in the neutron dose rates measured both inside and outside the satellites.

Comparing the data of Tables 1 and 2 it is seen that the fast neutron flux densities measured by the two different methods are in approximate agreement. A difference in the dose rates shown is probably due to different values of the fux-dose coefficients used.

Analyzing the measurement results has shown that the neutron flux density does not exhibit any unambiguous dependence on altitude, orbital inciination. and phase of the solar cycle. According to Jenkins et al. (1971), the flux density of the albedo neutrons with $E_{\mathrm{n}} \geqslant 1 \mathrm{MeV}$ increases by a factor of $\sim 10$ as a satellite moves from the equator to the poles and is $0.03 \mathrm{n} \mathrm{cm}^{-2} \mathrm{~s}^{-1}$ at the equator and $0.2-0.5 \mathrm{n} \mathrm{cm}^{-2} \mathrm{~s}^{-1}$ at the poies. This is confirmed by our experiments (see Table I) where the fast-neutron dose decreases by a factor of $\sim 3$ as the orbit inclination angle varies from 60 to $30^{\circ}$.

Analyzing the measurement results has also shown that the albedo neutron contribution to the total neutron flux may reach $\sim 50 \%$, which is in good agreement with the estimate obtained by Yushkov 
(1988) where the albeco neutron contribution to the cocal counting rate oi the neutron decector thown on Salyut -6 was lound to be $2 ! 3$.

it is of interest to escimate the neutron contrioution to the toral dose in low Earh orbit. This is possibie since thermoluminescent de:ectors were used in all or the light experiments. The races of absoribed neutron doses are approximately a iew per cent oi the tocal absorbed dose, whereas the neutron contribution to the dose equivalent reaches $20-30 \%$ (because of a bigh quality (actor).

In order to understand better the narure of the cosmic ray neutron component in low Earth orbit and in order to make the absolute dose measurements more accurate. it is necessary to carty out furcher experiments on board oriented spacecraft in different orbics and during varying phases of the solar cycle. The distribution of shielding mass about the detectors. must also be taken into accoune. Lastly, further refinement of the measurement techniques is still necessary.

\section{REFERENCES}

Akatov Yu. A.. Arkhangeisky V. V., Alexsandrov A. P.. Fehèr I., Deme S., Szabó B., Vagvōlgyi J., Szabó P. P.. Csöke A., Ránly M. and Farkas B. (1984) Taermoluminescent dose measurements on board Saiyut-type orbital stacions. Ado. Space Res. 4(10), 77.

A katov Yu. A., Vikhrov A. I., Dudkin V. E., Marenny A. M.. Veredov N. A.. Potapov Yu. V., Spurny F., Turek $\mathrm{X}$ and Hashegan D. (1981) Study of cosmic radiation $X$. and Hashegan D. (1981) Stud iaf. Third All-Union Conf. Prot. Against lonizing Radiat. Nuct. Tech. Instal lasion. Tbilisi.

Armstrong T. W., Chandler K. C. and Barish J. (1973) Caiculations on aeutron flux spectra induced in the Earth's atmosphere by galactic cosmic rays. J. geophys. Res. 78. 2715 .

Benton E. V. (1986) Summary of radiation dosimetry results On US and Sovier manned spacecraft. XXVI COSPAR Meeting, Toulouse, 1986. COSPAR Pape: No. VII. p. 7.
Benton E. V. and Henke R. P. (198j) Radiation exposures during space tight and their measurements. Adv. Space Res. 3(8). 171 .

Benton E V Genke R. P. and Psie:son D. D. i (977) P!astic auclear track desector messurements of high-LET parucle radianon on Apoilo. Sicylab and ASTP soace missions. Vucl. Track Detection 1. 2T.

Bhat $V$ (1976) Veutron high-energy soectra at imbar near the geomagnetic equator. J. zeopinys. Res. 31. 1603.

Dudkin Y E. Kovalev E. E.. Novikova N. R. Ostroumov v. Potapov Yu. V.. Skrorsov S. S. and Smirenny L. $V$. (1968) Measuring the proton and neutron spectra and fluxes on board satellites of the Cosmos series. Kosm. Issled. VI. 887.

Fishman G. J. (1974) Veutron and proton activation measuremeats trom Skyiab. AlAt Paper No. 74-1217. AlAdiAGD Conf. scient. Experiments Skylab. Octooer 1974. Huntsvilie. Alabama.

Hewitt J. E.. Schaefer H. J. and Sullivan J. J. (1972) Radiation exposure during the biosateilite III primate light. Hlth Phys. 23, 461 .

Jenkins R. W.. Ifediii S. O., Lockwood J. A. and Razdan H. (1971) The energy depeadence of cosmic-ray neutron leakage lux in the range of $0.01-10 \mathrm{MeV}$. J. geophys. Res. 76, 7470 .

Lingenfeiter R. E. (1963) Cosmic ray neutron leakage dux. J. geoophys. Res. 68, 5653.

Verxer M. B. (1973) The concribution of galactic cosmic ays to the amospheric seutron maximum dose equivaleat as a function of neutron egergy and aitirude. Filth Phys. 25, 524.

Merker M. B., Light E. S., Mendeil R. B. and Korf S. A. (1970) The tux of fast neutrons in the amospinere. Acta physiol. hung. 29 (Suppi. 2), 739.

Vemez F and Gorman Yu. Y. (1915) Harabook on Vuclear Physics. p. 386. Naukova Dumka. Kiev.

Perilov V. A.. Loszkin O. V. and Ostroumov V. I. (196z) Vuclear Reactions Induced by Hign-energy Particies. Acad Sci. U.S.S.R. Editorial Board. Moscow.

Vikhrov. Sci. Dudkin V. E.. Kovalev E. E., Komocbkov $\checkmark$. Lebeder $V$. N.. Litvinova E. G., Mirricas V. G.. Potapov Yu. V.. Potemion E. L.. Sichov B. S. and Frolov V. V. (1978) Arlas of Dose Characieristics of Exsemal Ionizing Radiarion (Edited by Kovaiev E. E.). Aromizdac. Moscow.

Yusingov B. Yu (1988) Measuring neutron tuxes on board Saiyut-6 orbital station. Kosm. lssled. 5. 793. 


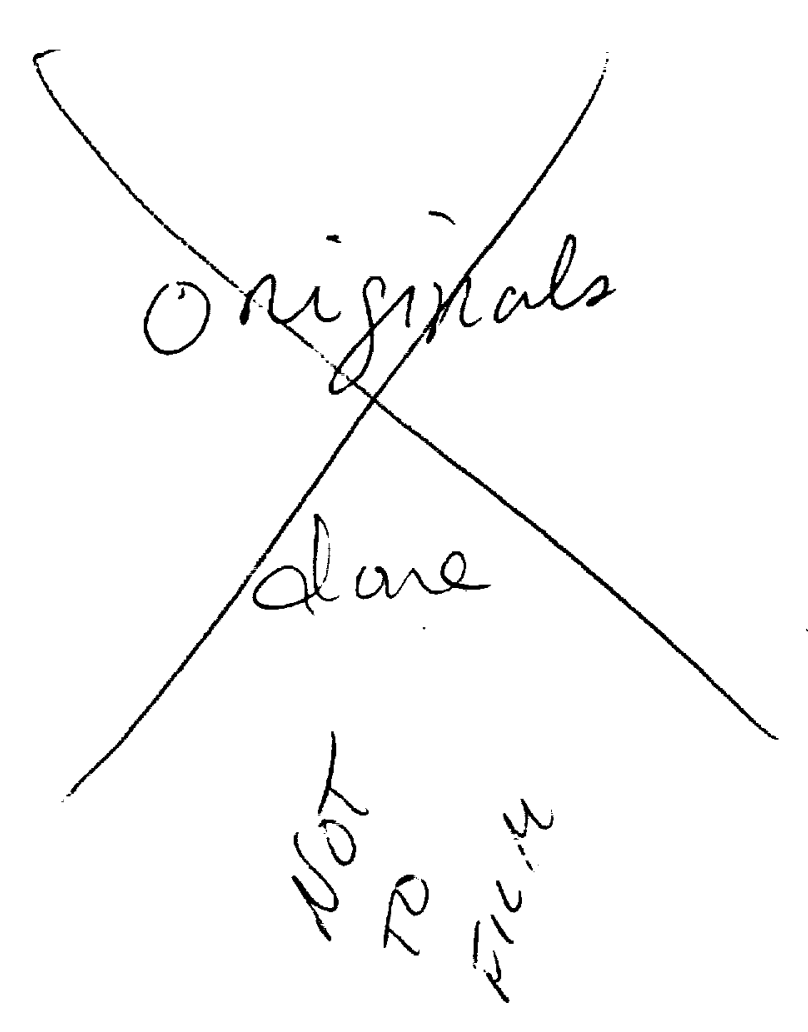

